\title{
Recent dramatic thinning of largest West Antarctic ice stream triggered by oceans
}

\author{
Antony J. Payne, ${ }^{1}$ Andreas Vieli, ${ }^{1}$ Andrew P. Shepherd, ${ }^{2}$ Duncan J. Wingham, ${ }^{3}$ \\ and Eric Rignot ${ }^{4}$ \\ Received 17 August 2004; revised 22 October 2004; accepted 4 November 2004; published 9 December 2004.
}

[1] A growing body of observational data suggests that Pine Island Glacier (PIG) is changing on decadal or shorter timescales. These changes may have far-reaching consequences for the future of the West Antarctic ice sheet (WAIS) and global sea levels because of PIG's role as the ice sheet's primary drainage portal. We test the hypothesis that these changes are triggered by the adjoining ocean. Specifically, we employ an advanced numerical ice-flow model to simulate the effects of perturbations at the grounding line on PIG's dynamics. The speed at which these changes are propagated upstream implies a tight coupling between icesheet interior and surrounding ocean. INDEX TERMS: 1827 Hydrology: Glaciology (1863); 3210 Mathematical Geophysics: Modeling; 9310 Information Related to Geographic Region: Antarctica. Citation: Payne, A. J., A. Vieli, A. P. Shepherd, D. J. Wingham, and E. Rignot (2004), Recent dramatic thinning of largest West Antarctic ice stream triggered by oceans, Geophys. Res. Lett., 31, L23401, doi:10.1029/2004GL021284.

\section{Introduction}

[2] The evolution of the West Antarctic ice sheet (WAIS) has been identified by many authors as a key uncertainty in our ability to predict future sea-level change [Church et al., $2001]$. The vast majority $(>90 \%)$ of mass lost from the ice sheet flows through a relatively small $(\sim 10)$ number of ice streams. An understanding of the long-term behaviour of these ice streams is therefore vital if we are to predict future sea level accurately.

[3] PIG has the largest discharge (66 Gt $\mathrm{yr}^{-1}$ ) of all WAIS ice streams. Together with its Amundsen-Coast neighbour Thwaites Glacier, it drains $\sim 40 \%$ (by volume) of the ice sheet (see Figure 1, top). The marine termini of these glaciers have been highlighted as potential sources of rapid retreat because of their lack of significant ice shelves and a bedrock topography which deepens considerably inland [Weertman, 1974]. Based on the mapping of hingeline positions using satellite radar interferometry [Rignot, 1998], the grounding line of PIG is known to have retreated between 1992 and 1996 at a rate of $1.2 \pm 0.3 \mathrm{~km} \mathrm{yr}^{-1}$ with an implied ice thinning rate of $3.5 \pm 0.9 \mathrm{~m} \mathrm{yr}^{-1}$. Satellite

\footnotetext{
${ }^{1}$ Centre for Polar Observation and Modelling (CPOM), University of Bristol, Bristol, UK

${ }^{2}$ Centre for Polar Observation and Modelling (CPOM), University of Cambridge, Cambridge, UK.

${ }^{3}$ Centre for Polar Observation and Modelling (CPOM), University College London, London, UK.

${ }^{4}$ Jet Propulsion Laboratory, California Institute of Technology, Pasadena, California, USA.
}

Copyright 2004 by the American Geophysical Union. 0094-8276/04/2004GL021284 radar altimetry over the period 1992 to 1999 confirms this rate at the grounding line but shows that the thinning extends remarkably far (over $200 \mathrm{~km}$ ) inland [Shepherd et al., 2001]. The thinning appears to be restricted to the domain of the ice stream where it averages $0.75 \pm 0.07 \mathrm{~m}$ $\mathrm{yr}^{-1}$. This rate is well above the levels expected from random variations in snowfall [Wingham et al., 1998], and is reflected in Thwaites Glacier and the adjoining Smith Glacier (averaging $0.55 \pm 0.09$ and $3.21 \pm 0.24 \mathrm{~m} \mathrm{yr}^{-1}$, respectively) [Shepherd et al., 2002]. This latter observation is important and points towards an external factor forcing the behaviour of all three ice streams, as opposed to internal surge-type variability. Repeat interferometry and sequential visible imagery available for 7 periods from 1974 to 2000 reveals two phases of acceleration in the flow of PIG (1974 to 1987 , and 1994 to 2000) separated by at least seven years of steady flow [Rignot et al., 2002; Joughin et al., 2003]. The magnitude of this acceleration (22\% overall) is sufficient to explain the observed thinning on the basis of flux balance calculations [Joughin et al., 2003], which implies a change in the flow dynamics of the ice stream.

[4] Although there is now a large body of observational evidence documenting changes in PIG on sub-decadal timescales, the modelling that is needed to identify their cause has received relatively little attention (with the notable exception of the study by Schmeltz et al. [2002]). The aim of this paper is therefore to use a numerical model of ice flow to determine whether an oceanic trigger can affect the deep interior of the ice stream on the appropriate timescales.

\section{Modelling}

[5] Changes in the flow of an ice stream, such as PIG, occur in response to changes in its force balance. We can therefore use the force balance to assess various hypotheses accounting for the observed acceleration and thinning discussed above. The force balance is between gravitational driving stress (proportional to the product of ice thickness and surface slope) and the sum of resistances from lateral drag (of slower flowing ice abutting the stream's margins), basal drag and longitudinal stress gradients within the stream [van der Veen and Whillans, 1989]. The ice streams of the glaciologically-distinct Siple-Coast sector (Figure 1, top) have a complex history of migration and stagnation on timescales of decades to centuries, which has been attributed to changes in the thermodynamics and hydrology of their beds. Similar processes may be affecting the basal drag experienced by PIG however the simultaneous thinning of all three Amundsen-Coast ice streams (PIG, Thwaites and Smith Glaciers) is difficult to reconcile with 

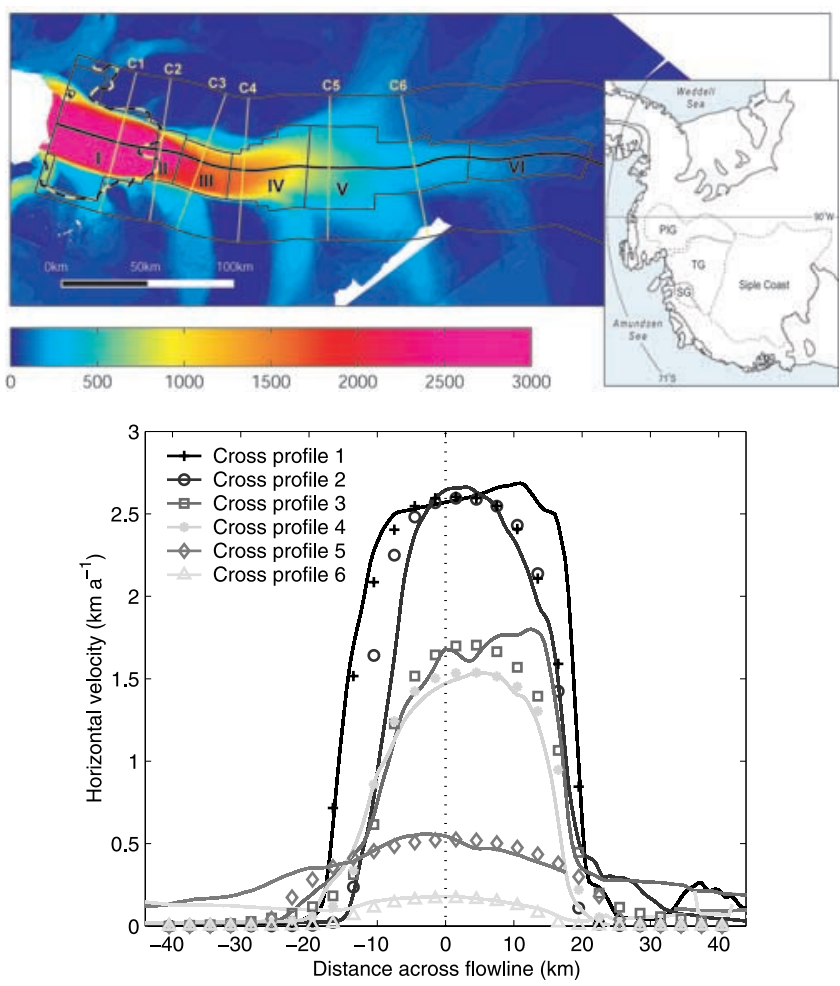

Figure 1. (top) The PIG model transect showing locations of cross-sections ( $\mathrm{C} 1$ to $\mathrm{C} 6)$ and regions in which the basal drag coefficient was calibrated (I is the ice shelf, II the ice plain, III the steepening, and IV to VI the trunk; basal velocity was set to zero outside of these regions). The background image shows ice-surface velocity magnitudes derived from interferometry. Inset shows map of the WAIS with locations of the three Amundsen Coast and Siple Coast ice streams, whose catchment areas are delineated by dashed lines. (bottom) A comparison of observed (dots) and modelled (lines) velocities at the six cross-sections.

this mechanism [Shepherd et al., 2002]. Changes in the width of an ice stream affect the lateral drag that it experiences [Whillans and van der Veen, 1997] and could also therefore explain PIG's acceleration. Satellite imagery of the area, however, shows little change in the lateral extent of the ice stream.

[6] Changes in either the driving stress or longitudinal stress gradients within the stream are therefore left as possible explanations. These changes could arise through the long-term retreat of the ice sheet from its maximum extent near the continental shelf break some 16,000 radiocarbon years before present [Lowe and Anderson, 2002]. This seems unlikely given that the observed rates of thinning would lead to complete decay within 600 years [Shepherd et al., 2001]. In addition, there is clearly a decadal element in the flow variability of PIG [Joughin et al., 2003]. A hypothesis that explains many of the observations is that PIG is responding to changes in drag in either its ice plain (a 10-km wide zone of low surface slopes associated with the grounding line) or ice shelf. These changes could be associated with iceberg calving [Rignot, 1998] or ice shelf/plain thinning in response to enhanced oceanic melting [Rignot, 2002], which then generate an initial perturbation near the grounding line that is then transmitted $\sim 200 \mathrm{~km}$ upstream throughout the interior of PIG. This mechanism could potentially explain the synchronicity of the changes along the Amundsen Coast, and has important implications for the influence of a changing ocean on the future stability of the WAIS. A major hurdle to the acceptance of this hypothesis is, however, that the time available for PIG to respond is very much shorter (tightly constrained by observations to be less than 20 years [Rignot et al., 2002; Joughin et al., 2003]) than the timescales previously thought possible. In the remainder of this letter, we employ an ice-flow model to determine whether this mechanism can realistically generate the observed thinning rates $\sim 200 \mathrm{~km}$ upstream of the grounding line on a decadal timescale.

[7] To test this hypothesis, we employ a newly-developed higher-order model of PIG's flow. The model consists of two main elements. The first is a three-dimensional representation of the stress balance within an ice mass, which incorporates all stress components (both vertical and horizontal) to first order (i.e., shear stresses are omitted from the vertical stress balance, however all terms are retained in the horizontal balances). It therefore avoids the key criticism of previous PIG modelling in that no questionable a priori assumptions about PIG's flow regime need to be made [e.g., Schmeltz et al., 2002]. The model solves the stress balance in elliptical form using Glen's flow law to substitute stresses with the appropriate strain rates [e.g., Pattyn, 2003]. The rate factor for ice deformation is held constant at a value determined by local ice temperature (assumed to vary linearly from observed air temperature at the ice surface to pressure melting point at the bed).

[8] The model employs realistic geometry along a transect from the ice-shelf front to the ice divide (Figure 2, top). Boundary conditions are zero velocity at the ice divide and lateral boundaries; zero stress at the upper subaerial and lower ice-shelf boundaries; and a force balance with the displaced ocean water at the shelf front. A viscous basal slip law with variable basal-drag coefficient is employed [MacAyeal, 1989] within the extent of PIG. Elsewhere the basal boundary condition is zero velocity. Observed icesurface velocities are used to calibrate the model primarily by tuning the basal-drag coefficient in the seven regions shown in Figure 1 (top). The resultant fit is very satisfactory (Figure 1, bottom). The second element of the model is the temporal evolution of ice thickness, which is allowed to vary as a consequence of the velocity fields generated by the stress model. This, again, is a new feature of the model compared to previous PIG studies.

[9] We employ this model in two separate applications. First, we use the three-dimensional stress-balance model to study the stress regime of PIG and its instantaneous response to change. Second, we employ a verticallyintegrated version of the stress model with temporal evolution of ice thickness to study the delayed response.

\section{Results: Instantaneous Response}

[10] Results from stress-balance model (Figure 2, middle) indicate that PIG has three distinct flow zones: the ice shelf and plain where all stress components are important; a $40-\mathrm{km}$ zone upstream of this in which driving stress is balanced almost completely by basal drag (we refer to this 

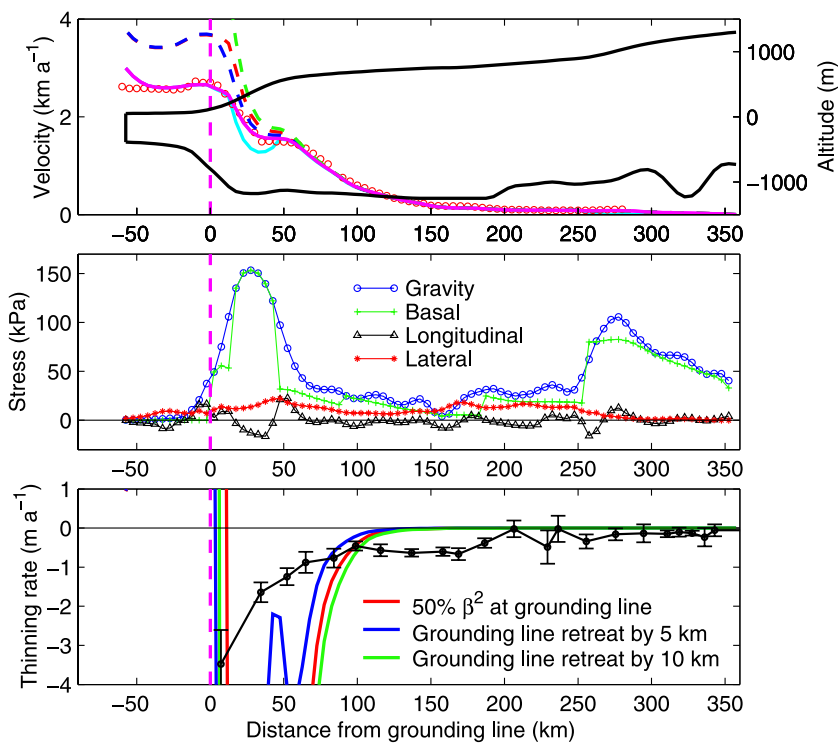

Figure 2. (top) Centreline geometry of the PIG model showing ice-surface velocity in calibrated model (in pink with interferometry observations as red dots and modelled basal velocity in light blue). Increased surface velocities generated in the perturbation experiments are also shown (red reduced ice plain basal drag, blue and green grounding line retreat). Vertical dashed line indicates the position of the grounding line. (middle) Modelled force balance in the calibrated model. (bottom) Instantaneous thinning rates produced by the perturbations shown with the observed rates (dotted line with error bars from altimetry).

zone as the 'steepening'); and the main 'trunk' of the ice stream in which basal and lateral drag are equally important (Figure 2, middle). The stress regime in the trunk is similar to that operating in the Siple Coast ice streams implying a substrate of similarly weak, subglacial sediments. The steepening, however, is characterized by very much higher basal drag implying that the substrate in this area is stronger (either hard bedrock or over-consolidated sediment).

[11] We now perturb the calibrated flow model in two grounding-line retreat scenarios, and in a third scenario in which the basal drag coefficient in the ice plain is reduced (simulating the effect of the reduced bed contact consequent on thinning and floatation). The snapshot results imply that the immediate mechanical effect of these perturbations is felt up to $100 \mathrm{~km}$ from the grounding line (Figure 2, bottom). This direct effect is brought about by acceleration as a reduction in basal/lateral drag is transmitted via longitudinal stress gradients upglacier. The changes in velocity produced in these experiments are consistent $(\sim 30 \%)$ with observations. The predicted accelerations cannot, however, explain the observed thinning over the entire extent of the ice stream (up to $\sim 200 \mathrm{~km}$ upstream of the grounding line) and, therefore, imply that an oceanbased trigger is unlikely.

\section{Results: Delayed Response}

[12] Faced with this apparent anomaly, we now investigate the effects of the perturbed velocity field on PIG's thickness. We do this in a time-dependent fashion by allowing the calculated stress and velocity distributions to affect the temporal evolution of ice thickness within the model, as well as allowing changing ice-surface geometry to affect gravitational driving in the stress model. Results from the three-dimensional model suggest that PIG experiences plug flow (no vertical shear) over the majority of its length (vertical shear accounts for a maximum of $\sim 17 \%$ of total flow at the steepening, Figure 2, top). This observation justifies the use (primarily for reasons of numerical efficiency and stability) of a vertically-integrated stress model (which assumes minimal vertical shear [e.g., MacAyeal, 1989]) in the time-dependent calculations described here. Further, the vertically-integrated version of the model generates results that are consistent with the three-dimensional results for the snapshot perturbation experiments discussed above.

[13] In the context of the long response times traditionally accorded to ice sheets, the results are surprising because they indicate that the initial anomaly can propagate far inland on very short, decadal timescales (Figure 3). Further numerical experiments indicate that the speed of this upstream propagation is a robust feature of our model and, we suggest, of the real PIG system.

[14] The transmission of a perturbation in ice thickness through an ice mass can be represented as the sum of source, kinematic-wave and diffusive responses [Nye, 1963]. Based on the observations for PIG, we estimate that the equivalent response times for the kinematic-wave and diffusion terms are $\sim 130$ and $\sim 20 \mathrm{yr}$, respectively (using a length scale of $200 \mathrm{~km}$, a downstream kinematic wave speed of $1.5 \mathrm{~km} \mathrm{yr}^{-1}$ and a diffusivity of $2000 \mathrm{~km}^{2} \mathrm{yr}^{-1}$;
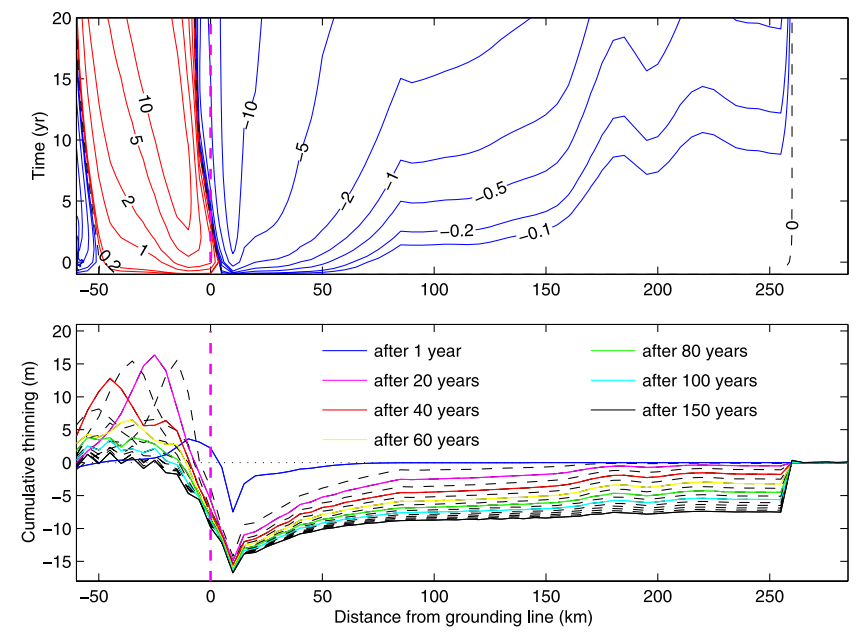

Figure 3. Cumulative changes in ice thickness generated by a reduction in basal drag in the ice plain. (top) In the first 20 years after the perturbation, showing a diffusive thinning in the grounded ice (blue) and an kinematic thickening in the ice shelf (red). (bottom) Evolution towards a nearly steady-state condition of $\sim 8 \mathrm{~m}$ thinning in the trunk of PIG after $150 \mathrm{yr}$ (coloured lines refers to times shown in legend, dashed lines spaced one decade apart for intervening periods). Plots refer to the response at PIG's centreline and dashed vertical line refers to the grounding line. Above $260 \mathrm{~km}$, the response is muted because this point marks the boundary between the fast-flowing PIG and slow-flowing inland ice. 
the latter calculated using an analytical expression for icestream flow [Raymond, 1996]). The timing of the modelled (and observed) upstream thinning is therefore consistent with a diffusive process. Our estimate of the diffusive response time is probably an underestimate because it incorporates kinematic effects but not the effects of longitudinal stress coupling. Acceleration in the ice plain produces a local increase in ice surface slope via down draw, which increases driving stress and leads to an acceleration of ice flow upstream of the original location. This mechanism has previously been hypothesized [Bindschadler, 1997; Joughin et al., 2003], however this is its first demonstration in a numerical model.

[15] In our numerical experiments, the initial acceleration is generated by a reduction in the basal drag coefficient of the ice plain, however we obtain very similar results in a range of experiments in which various aspects of the rheology and geometry of the ice shelf are perturbed. We hypothesize that in the real ice stream this loss of drag is a consequence of reduced ice grounding in the area, itself caused by the thinning occasioned by enhanced oceanic melt.

\section{Discussion}

[16] The numerical experiments reported here do not lead to catastrophic retreat. A new equilibrium is attained after approximately 150 years with a total thinning of $\sim 8 \mathrm{~m}$ over the majority of PIG and $16 \mathrm{~m}$ in the ice plain. However, it is important to note that this is the response to a single, instantaneous change in the ice plain. In reality, ice-plain thinning (and loss of basal drag) may well continue into the future (especially if they are indeed brought about by increased oceanic melt), in which case the eventual response of PIG would be far greater.

[17] It should also be stressed that the simulation does not include a potential positive feedback in the ice plain, where thinning is associated with reduced grounding and a further reduction in basal drag (in the experiments the perturbed basal drag coefficient is held constant after the initial perturbation). Our knowledge of the subglacial topography in this area is not yet sufficient to allow a parameterization of this effect. The modelled thinning of PIG is accompanied by thickening of its ice shelf (Figure 3 ). This thickening has not been seen in satellite observations although its magnitude is greater than the estimated error of such observations [Shepherd et al., 2003]. This disparity may imply that recent increases in mass loss from the ice shelf by oceanic melt are large enough to mask this thickening.

[18] In conclusion, our results show that changes in PIG's ice shelf and/or ice plain can be transmitted rapidly upstream on decadal timescales. It therefore appears likely that the observed widespread thinning in the interior regions of PIG is a response to recent changes in the oceanography of the Amundsen Sea, which we postulate caused increased basal melt and thinning of PIG's ice plain. The results suggest that the presence of ice streams strengthens the coupling between coastal areas and the deep interior of WAIS.

[19] Acknowledgments. We acknowledge the efforts of our editor and two anonymous reviewers in improving the clarity of the final manuscript. This work was supported by the UK Natural Environment Research Council's standard grant NER/A/S/2000/00419 and by their funding of the Centre for Polar Observation and Modelling.

\section{References}

Bindschadler, R. (1997), Actively surging West Antarctic ice streams and their response characteristics, Ann. Glaciol., 24, 409-414.

Church, J. A., et al. (2001), Changes in sea level, in Climate Change 2001: The Scientific Basis, edited by J. T. Houghton et al., pp. 639-694, Cambridge Univ. Press, New York.

Joughin, I., E. Rignot, C. E. Rosanova, B. K. Lucchitta, and J. Bohlander (2003), Timing of recent accelerations of Pine Island Glacier, Antarctica, Geophys. Res. Lett., 30(13), 1706, doi:10.1029/2003GL017609.

Lowe, A. L., and J. B. Anderson (2002), Reconstruction of the West Antarctic ice sheet in Pine Island Bay during the Last Glacial Maximum and its subsequent retreat history, Quat. Sci. Rev., 21, 1879-1897.

MacAyeal, D. R. (1989), Large-scale ice flow over a viscous basal sediment: Theory and application to ice stream B, Antarctica, J. Geophys. Res., 94(B4), 4071-4087.

Nye, J. F. (1963), The response of a glacier to changes in the rate of nourishment and wastage, Proc. R. Soc. London, Ser. A, 275, 87-112.

Pattyn, F. (2003), A new three-dimensional higher-order thermomechanical ice sheet model: Basic sensitivity, ice stream development, and ice flow across subglacial lakes, J. Geophys. Res., 108(B8), 2382, doi:10.1029/ 2002JB002329.

Raymond, C. F. (1996), Shear margins in glaciers and ice sheets, J. Glaciol., 42, 90-102.

Rignot, E. (1998), Fast recession of a West Antarctic glacier, Science, 281, $549-551$

Rignot, E. (2002), Ice-shelf changes in Pine Island Bay, Antarctica, J. Glaciol., 48, 247-256.

Rignot, E., D. G. Vaughan, M. Schmeltz, and T. Dupont (2002), Acceleration of Pine Island and Thwaites Glaciers, West Antarctica, Ann. Glaciol., 34, $189-194$.

Schmeltz, M., E. Rignot, T. K. Dupont, and D. R. MacAyeal (2002), Sensitivity of Pine Island Glacier, West Antarctica, to changes in ice-shelf and basal conditions: A model study, J. Glaciol., 48, 552-558.

Shepherd, A., D. J. Wingham, J. A. D. Mansley, and H. F. J. Corr (2001), Inland thinning of Pine Island Glacier, West Antarctica, Science, 291, $862-864$.

Shepherd, A., D. J. Wingham, and J. A. D. Mansley (2002), Inland thinning of the Amundsen Sea sector, West Antarctica, Geophys. Res. Lett., 29(10), 1364, doi:10.1029/2001GL014183.

Shepherd, A. P., D. J. Wingham, T. Payne, and P. Skvarca (2003), Larsen Ice Shelf has progressively thinned, Science, 302, 856-859.

van der Veen, C. J., and I. M. Whillans (1989), Force budget: I. theory and numerical methods, J. Glaciol., 35, 53-60.

Weertman, J. (1974), Stability of the junction between an ice sheet and an ice shelf, J. Glaciol., 13, 3-11.

Whillans, I. M., and C. J. van der Veen (1997), The role of lateral drag in the dynamics of ice stream B, Antarctica, J. Glaciol., 43, 231-237.

Wingham, D. J., A. J. Ridout, R. Scharroo, R. J. Arthern, and C. K. Shum (1998), Antarctic elevation change from 1992 to 1996, Science, 282, $456-458$.

A. J. Payne and A. Vieli, CPOM, University of Bristol, University Road, Bristol BS8 1SS, UK. (a.j.payne@bristol.ac.uk)

E. Rignot, Jet Propulsion Laboratory, California Institute of Technology, MS 300-235, Pasadena, CA 91109-8099, USA.

A. P. Shepherd, CPOM, Scott Polar Research Institute, University of Cambridge, Cambridge CB2 1ER, UK.

D. J. Wingham, CPOM, University College London, Gower Street, London WC1E 6BT, UK. 